\title{
SMART AGRO-ROBOT - AN INNOVATIVE APPROACH
}

\author{
Mrs. Shweta Suryawanshi \\ Department of ENTC \\ DYPIEMR, Akurdi, Pune, Maharashtra, India
}

\begin{abstract}
Agriculture is one of our most important industries, providing food, feed and fuel necessary for our survival. Over the past $\mathbf{4 0}$ years, there has been gradual fall in the contribution of agriculture to the GDP. This could be attributed to the present generation's lack of interest towards farming as there are other easier ways of survival over farming.

Technology has found solutions for every problem, so the problem encountered in farming also can be addressed by the application of technology. "Agriculture is the backbone of India". And yet we see that agriculturists, rather the farmers, happen to be the people who work the hardest, resulting in a rapid decline in the number of people opting for this job. The growing population demands an increased need for food.

Keywords-
1. Raspberry Pi/Arduino UNO(ATMEGA328P)/
2. Solar Panel/ Power supply
3. Camera
4. Moisture sensor
5. Temperature and Humidity sensor
6. Cultivator
7. Seed Dispenser
8. Water Pump

\section{INTRODUCTION}

Agriculture is one of our most important industries, providing food, feed and fuel necessary for our survival. Over the past 40 years, there has been gradual fall in the contribution of agriculture to the GDP. This could be attributed to the present generation's lack of interest towards farming as there are other easier ways of survival over farming.

Technology has found solutions for every problem, so the problem encountered in farming also can be addressed by the application of technology. "Agriculture is the backbone of India". And yet we see that agriculturists, rather the farmers, happen to be the people who work the hardest, resulting in a rapid decline in the number of people opting for this job. The growing population demands an increased need for food.

This project presents an automated robot, named 'AGROROBOT', that can ease the work of our 'bread-yielders'. The

\author{
Mr. Rahul Padole \\ Department of ENTC \\ DYPIEMR, Akurdi, Pune, Maharashtra, India
}

Agro-Robot being a multipurpose robot, not only reduces the efforts required by the farmer, but also is a solution to the declining number of people opting for this occupation.

A single bot can perform several tasks thereby greatly reducing the number of labours involved. The agro-robot has also served as a solution to the toils that a farmer faces and thus farming activities could be done with a click of a button. Another factor that has to be considered during the inception of the robot was the cost effectiveness to enable its availability to all Indian farmers.

The agro-robot would enable a drastic increment in yield and set agriculture back as a major contributor to the wealth of the nation

\section{PROPOSED ALGORITHM}

In the current scenario most of us have come across atomization in various fields particularly in agricultural field, as the advancement of technology has to a lead tremendous development in the industrial products that have made our lives a lot easier and helpful than what our ancestors faced. The advancements especially in the field of agriculture have helped evolve a new era of development and growth of different developing countries. The atomization in this field has been a trademark for the people who are completely dependent on agriculture for their survival and other needs.

Accordingly to survey from which reports were made, which says most of the agriculture equipments projected in various fields is either by researchers or by the engineers and they are practically very difficult to implement. Focussed on need of increase in productivity \& reduction of labour on which researches are done, instead of manually handling equipment, it can be controlled remotely, which can perform various functions particularly in agricultural field like ploughing, sowing and harvesting, irrigating, etc. Hence, doing complex operations within specified time. In rural areas the main problem is load shedding it can be overcome by using renewable energy source through solar panel.

These equipments made are mostly very complex in terms of field operation or are either less efficient as they are implemented based upon on the basic concept from the design point of view. Many of the other devices developed based upon the concept of seed sowing and fertilizing are either a 


\section{International Journal of Engineering Applied Sciences and Technology, 2019 \\ Vol. 4, Issue 8, ISSN No. 2455-2143, Pages 180-181 \\ Published Online December 2019 in IJEAST (http://www.ijeast.com)}

single application device or they are very less efficient. This because these devices are developed by taking in point the present scenario in the field of agriculture.

The below figure shows block diagram of smart agrobot using raspberry pi. The various components interfaced in the block diagram are Soil moisture sensor, DC motors to drive the agrobot, Raspberry Pi camera, Seeding mechanism for seed distribution, solar panel, battery, water pump, 4x4 bot, Arduino Uno and cultivator mechanism.

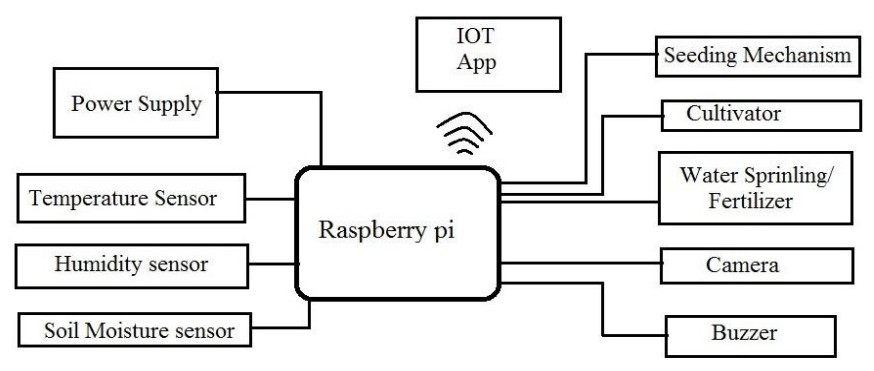

1. Cultivating: This application is very easily achieved by attaching the metal like structure at the back side of the robot. For this application we require to give good mechanical strength to the robot, because it is quit heavy and when it is place on soil for ploughing purpose, it required extra force to move forward. This is the initial operation in the farm. This application has no delay time. Once it place on the farm It continuously cultivating the soil through the cultivating tool.

2.Seed Distribution: The dropping of seed is done using the dc motor seed sowing mechanism. For this, we are using the special slotted wheel connected to the shaft of DC motor. The seeds fall through the funnel from top of the seed storage tank. The slots in mechanical slotted wheel is wide enough to contain the space for occupying the seed. The user can give a command as and when required to the Raspberry Pi via his android phone which will then turn on the motor to start the seed sowing operation.

3.Camera: It is used for robot guidance and for capturing live video feed of the field. It can be used for taking snapshots of various types of crops to check whether it is of good quality or not. Camera can be rotated at different points according to our area of interest and also provides view for the path.

4. Irrigation: A pump is used to sprinkle the water, depending on the moisture content present in the soil. A soil moisture sensor senses the moisture content present in the soil and then the data sent can be used for sprinkling water in the field according to the need.
5. Plant monitoring: The camera used here can be used to provide a live feed of the field. This can be useful for later processes in agriculture to detect whether a crop if of good quality or not.

\section{CONCLUSION}

1. This project will overcome some problems in agriculture.

2. The rapid growth in the industries is influencing the labours who are situating in the villages to migrate to the cities. Thus creating the labour problem for agriculture. The wages for the labour is also more.

\section{REFERENCE}

1. Blackmore Simon, Stout Bill, Wang Maohua, Runov Boris; June (2005) Robotic Agriculture the future of agricultural mechanisation.

2. Varma H., Mulla C., Raut, Dr. Pawar V. R. (2017) Fertigation Irrigation System for Agricultural Application along with Soil Monitoring using IoT.

3. Saher Mairaj, Architkeshav Gangaland Farheen (2017) Agricultural Automation System with Field Assisting Robot-AgroBot.

4. Dr.V .Vidya Devi, Kumari G. Meena (2013), "RealTime Automation and Monitoring System for Modernized Agriculture" ,International Journal of Review and Research in Applied Sciences and Engineering (IJRRASE) Vol3 No.1. PP 7-12,

5. Griepentrog, Hans W., Jger, Claes Lund Dhring; Jger, Karina Dhring (2012) Electric Agricultural Robot with Multi-Layer-Control. Paper presented at International Conference of Agricul- tural Engineering, Valencia, Spain. 